\title{
Kernos
}

Revue internationale et pluridisciplinaire de religion

grecque antique

2| 1989

Varia

\section{B. Zannini Quirini, NEPHELOKOKKYGIA. La prospettiva mitica degli Ucelli di Aristofane}

\section{Fabio Mora}

\section{(2) OpenEdition}

\section{Journals}

Édition électronique

URL : http://journals.openedition.org/kernos/266

DOI : $10.4000 /$ kernos.266

ISSN : 2034-7871

Éditeur

Centre international d'étude de la religion grecque antique

\section{Édition imprimée}

Date de publication : 1 janvier 1989

Pagination : 270-271

ISSN : 0776-3824

\section{Référence électronique}

Fabio Mora, «B. Zannini Quirini, NEPHELOKOKKYGIA. La prospettiva mitica degli Ucelli di Aristofane », Kernos [En ligne], 2 | 1989, mis en ligne le 04 mars 2011, consulté le 23 septembre 2020. URL : http:// journals.openedition.org/kernos/266 ; DOI : https://doi.org/10.4000/kernos.266 
de la recherche philologique et ne mette pas en valeur les apports de l'archéologie concernant les sujets abordés.

Ioannis LOUCAS

\author{
B. ZANNINI QUIRINI, NEPHELOKOKKYGLA. La prospettiva mitica degli \\ Ucelli di Aristofane, Roma, "L'Erma» di Bretschneider, 1987, 159 p. (Storia \\ delle Religioni, 5).
}

L'A. présente une interprétation originale des Oiseaux d'Aristophane inspirée du point de vue historico-religieux des études de A. Brelich sur le drame ancien, qui soulignent le caractère sacré de la comédie archaïque en la comparant aux mythes des tricksters.

Trois noyaux se dégagent dans sa recherche : le caractère de Térée (p. 2144), les correspondances entre la rébellion des oiseaux et la gigantomachie (p. 45-87), le thème de la souveraineté primordiale des oiseaux (p. 89-145).

L'A. passe en revue les diverses traditions relatives à Térée (sa transformation en huppe, chez la plupart des auteurs, et quelques variantes), qui peuvent coexister sans qu'on puisse tracer l'évolution du récit. Il relève aussi les affinités entre Térée et la huppe : le même caractère guerrier, royal, sauvage, une alimentation sale, le parallélisme entre la poursuite de Procnè et de Philomèle et la façon dont les huppes molestent hirondelles et rossignols. Moins convaincante est l'idée que la métamorphose de Térée correspond aux transformations de la huppe aux diverses saisons (p. 28 sq.). Pour l'A., il s'agit d'un mythe de différenciation d'êtres primordiaux qui ne sont pas encore hommes ni animaux (p. 38). On peut cependant se demander si la coexistence de traits humains et animaux, notamment dans le chœur, doit être expliquée par ce manque de distinction : le développement incomplet d'une substitution est une face essentielle du comique d'Aristophane.

En examinant la gigantomachie comme modèle de la rébellion des oiseaux, l'A. refuse l'hypothèse de $\mathrm{F}$. Vian pour qui cette comédie témoigne d'une ancienne version, inconnue par ailleurs, de la titanomachie, le motif de la guerre étant la nourriture d'immortalité. La menace des oiseaux d'intercepter la fumée des sacrifices se réfêre à la séparation entre hommes et dieux, sanctionnée par le partage des victimes à Mécônè. L'A. interpète donc, d'une façon suggestive et intéressante, la rébellion des oiseaux du point de vue du refus orphique du sacrifice. Les habitants de Nephelokokkygia se situent avant et en dehors de l'ordre des choses et donc virtuellement contre lui (p. 51 sq.). Plusieurs traits des oiseaux les rapprochent des Géants : leur plumage, leur caractère sauvage, la durée exceptionnelle de leur vie et (au moins en partie) leur refus de l'ordre et de la culture. L'A. analyse aussi les personnages mythiques de la comédie (p. 63-80) : Iris, dont il souligne les traits pré-polythéistes; Prométhée, qui chez Eschyle donne à Zeus la victoire sur les Titans, mais ici se révolte avec les oiseaux; Héraclès, qui ne défend 
plus l'ordre contre les rebelles; Poséidon; Triballos, qui correspond bien aux traditions mythiques sur les sauvages Triballoi. Le couple Pisthetairos / Basileia est opposée à celui de Zeus / Héra.

Même si nous acceptons les critiques que l'A., après Brelich, adresse aux interprétations utopiques de la cité des oiseaux, il faut souligner le caractère sérieux des utopies grecques : pour nous, dans les Oiseaux, il n'y a pas refus d'une réalité complètement différente qui aurait pu arriver, mais condamnation d'un nouvel arrangement qui gâterait le monde plutôt que de l'améliorer. Si Aristophane refuse les modèles utopiques pour leur absurdité, il est malgré tout sensible aux tendances réformatrices : cette question aurait mérité une plus grande attention. Il nous semble que l'A. a trop insisté sur une idée de Brelich (la comédie est le lieu du comme cela serait si où le respect des valeurs s'avère nécessaire) au détriment d'une autre intuition du même auteur (le dramaturge ne prend jamais parti pour aucun de ses personnages).

La royauté des oiseaux se manifeste de diverses manières : leur crète, leur nature d'êtres primordiaux, leur pouvoir d'annoncer périodiquement une nouvelle réalité (le jour ou les saisons). Aristophane aurait puisé ces éléments à un répertoire mythique pré-polythéiste que l'A. présente de manière convaincante, mais nous n'acceptons pas l'hypothèse selon laquelle Aristophane aurait été conscient de l'antériorité historique de ces matériaux par rapport aux croyances polythéistes (p. 130): du point de vue grec, les croyances sauvages sont une dégradation du polythéisme et non des antécédents - ce qui les rendrait plus "vraies».

L'A. étudie ensuite l'uornithogonie» des Oiseaux (v. 693-702). Ses éléments appartiennent à une culture qu'exclut la Théogonie d'Hésiode, ce qui fait de cette cosmogonie délibérément ridicule une parodie des cosmogonies orphiques (p. 144).

Il conclut en résumant son interprétation de la méthode d'Aristophane : pour lui le comique veut conforter le système culturel athénien en soulignant l'altérité de Nephelokokkygia, consolider les structures polythéistes de la cité en démontrant que le refus du présent pourrait aboutir à un retour aux origines qui, au contraire, doivent être tenues pour révolues.

Ces conclusions sont d'un grand intérêt, même si elles sont formulées de manière un peu tranchante; elles ne se bornent pas à une interprétation qui ne chercherait dans les situation dramatiques de la comédie que l'expression immédiate des idéaux de l'auteur. On ne peut que souhaiter voir se multiplier, à partir d'un tel point de vue historico-religieux, des études plus attentives à la culture d'Aristophane, à ses méthodes, à son jeu complexe entre fiction théâtrale et réalité, à la relation entre conservatisme et intérêt pour les idées nouvelles.

Fabio MORA 